\title{
Assessment the Present Status of Batticaloa Lagoon, Sri Lanka by means of Water Quality, Fish Diversity Indices and Pollution Indicating Planktons
} Jalaldeen Mohamed Harris* and Periyathamby Vinobaba

Department of Zoology, Faculty of Science, Eastern University, Sri Lanka

\begin{abstract}
Abiotic and biotic variables of coastal lagoons are highly heterogeneous in both space and time, and this heterogeneity complicates the assessment of lagoon ecological status. These variables are essential for monitoring and preserving of these fragile ecosystems and the resources and services they sustain. This study was designed to assess the effect of lagoon water quality on changes in fish abundance. In situ measurements of chemical and physical parameters of the Batticaloa lagoons were measured fortnightly by using a calibrated portable Hanna instruments over the different seasons from March 2012 to February 2013. Fish diversity indices for the main commercial species were calculated. Fish composition varied greatly according to the study site and the seasonal trends. Results reveal that the existing conditions, such as salinity dissolved oxygen, nitrate and $\mathrm{pH}$ had a strong effect on the fish community in the lagoon. The present study is commissioned to assess the seasonal variation and the status of the lagoon to make informed plans for the fishery of the lagoon patients to reap it successfully and sustainably.
\end{abstract}

Keywords: Diversity; Lagoon; Season; Water quality

\section{Introduction}

Estuaries and lagoons represent about $13 \%$ of coastal areas worldwide and exhibit very diverse characteristics in terms of surface area, shape, freshwater input, connections to sea, and anthropogenic impact [1]. Lagoons are very important ecosystems that offer variety services: provisioning, such as the production of food and water; regulating of gases, supporting, such as nutrient cycles; and cultural, such as spiritual and recreational benefits [2]. Thus, it is necessary to periodically assess the physical, biological and chemical relationships that may determine ecological health of lagoons. The coastal lagoon has historically played a crucial role in human life. A large proportion of the human population inhabits coastal areas [3] and human density there is expected to increase in the coming years. Consequently, coastal ecosystems are particularly exposed to human pressures, and some of them are among the most disturbed parts of the biosphere [2]. Biological measures should be capable of reflecting the integrity of the entire ecosystem. Ideally, disturbance effects on the complete assemblage of organisms should be studied; however, a particular assemblage or a key component is often measured as being representative of the entire community. Measuring of diversity indices is essential for stabilization of ecosystem and predicts the overall environmental quality for better understanding intrinsic worth of all species distribution [4]. The quality of water should be checked at regular interval to prevent the deterioration of water quality and to maintain the aquatic biota. Uncontrolled discharge of untreated effluent water, litter, sediment carrying runoff as well as solid waste into the lagoon has degraded the quality of surface water beyond the acceptable limits [5]. Fish assemblages may differ on longitudinal gradient in streams according to various biological aspects such as species diversity, stress tolerance, habitat preferences, feeding behaviors and origin of species [6]. Fish assemblages have widely been used as ecological indicators to assess and evaluate the level of degradation and health of aquatic body at various spatial scales [7]. Although fish communities may have a high degree of natural variability, they can be useful indicators of ecosystem health [8]. Several authors revealed that, both phytoplankton and zooplankton communities have been successfully used in coastal water quality monitoring and as bio indicators of pollution [9]. Furthermore, the phytoplankton will reflect the condition of the waters, not only at the time of sampling, but also the condition of the previous time [10]. Present investigation was under taken to study the distribution ichthyo diversity of Batticaloa lagoon, Sri Lanka in different locality along with hydro chemistry and planktons to evaluate the present ecological status of this lagoonaiming to contribute a better knowledge for conservation planning of lagoon environments. In addition suggest the measure for improvement of fish production to uplift the livelihood of fisher folks of this region.

\section{Lagoon Characteristics}

Batticaloa lagoon located in east coast of Sri Lanka located between $7^{\circ} 24^{\prime}-7^{\circ} 46^{\prime} \mathrm{N}$ and $81^{\circ} 35^{\prime}-81^{\circ} 49^{\prime} \mathrm{E}$. The lagoon is about $56.8 \mathrm{~km}$ long along meridian axis and it varies widely $0.5 \mathrm{~km}$ to $4 \mathrm{~km}$. It opens up to the Indian Ocean via the two inlets one at Palameenmadu and the other at Kallar shown in Figure 1. The lagoon is shallow with irregular bottom topography. Three distinct longitudinal zones could be recognized in this lagoon, the upper saline zone, the middle transitional zone with salinity fluctuations and the lower zone which is predominately fresh water zone. The seawater intrusion ranges from approximately 1 to $2.5 \mathrm{~km}$ from the mouth depending upon flow conditions of sea water. At present, the lagoon covers area of approximately 135.5 square kilometers. The climate of the study area comprises a wet season during North-East monsoonal period (November to February) characterized by high mean precipitation $(1250 \pm 230 \mathrm{~mm})$, and a dry season during the South-West monsoonal period (May to August) marked by low mean precipitation $(300 \pm 23 \mathrm{~mm})$. In between two inter monsoonal periods are exist such as first inter monsoon (March to April) and second inter monsoon (September to October).

${ }^{*}$ Corresponding author: Jalaldeen Mohamed Harris, Department of Zoology, Faculty of Science, Eastern University, Sri Lanka, E-mail: harriseusl@gmail.com

Received May 09, 2013; Accepted July 18, 2013; Published July 22, 2013

Citation: Harris JM, Vinobaba P (2013) Assessment the Present Status of Batticaloa Lagoon, Sri Lanka by means of Water Quality, Fish Diversity Indices and Pollution Indicating Planktons. J Biodivers Endanger Species 1:105. doi:10.4172/ पियदियद.1000105

Copyright: $\odot 2013$ Harris JM, et al. This is an open-access article distributed under the terms of the Creative Commons Attribution License, which permits unrestricted use, distribution, and reproduction in any medium, provided the original author and source are credited. 
Citation: Harris JM, Vinobaba P (2013) Assessment the Present Status of Batticaloa Lagoon, Sri Lanka by means of Water Quality, Fish Diversity

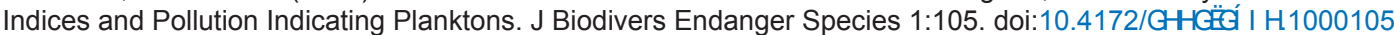

\section{Material and Methods}

16 sampling points were previously defined based on the different biotypes in the lagoon shown in Figure 1 by their different characteristics. The precise location of each station was determined using a portable GPS unit (Table 1). Points 1 and 13 were located near the bar mouth connections with Bay of Bengal and both presented muddy bottom. Point 5 presented the greatest concentration of marginal vegetation and was situated on the northwest section of the lagoon. Point 6 was located near the shrimp farming site on the northern sector with clay bottom. Points 3, 7 and 10 are showing the highest levels of industrial pollution. Points 12-16 in the main freshwater area, highly organically enriched with abundance of aquatic vegetation. The substratum profiles at the stations 3 and 4 were similar and characterized by fine muddy silt stations $3,4,10$ and 14 were situated nearer the sewage discharge.

Water samples for key physico-chemical parameters (salinity, dissolve oxygen, turbidity, , nitrate, phosphate and $\mathrm{pH}$ ) were collected as per standard method [11] from the selected locations by dipping well labeled sterilized plastic containers of $250 \mathrm{ml}$ to about $6-10 \mathrm{~cm}$ below the surface film and were analyzed and storage at $-4^{\circ} \mathrm{C}$ in refrigerator. Plankton samples were collected by using sterilized, $500 \mathrm{ml}$ wide mouth plastic container at each sampling station and immediately fixed in lugol's solution as ratio of 100:1 per sample and lugol's solution. The samples were reduced to $10 \mathrm{ml}$ by decanting the supernatant aliquot and centrifuged in Gallenkamp centrifuge for 20 minutes at $4 \mathrm{rpm}$. Identification and enumeration were done by using Olympus C011 (Japan) binocular microscope using key to genera of Algae [12] and species were identified to the lowest taxonomic level. The same procedure also used for the zooplankton studies and identified with aid of practical manual for students of costal marine Zooplankton [13].

The lagoon ichthyofauna was sampled fortnightly during the period from March 2012 to February 2013. A dugout canoe with paddles was used for sampling at the various stations. Mainly cast net (3/8" square mesh size and 3/4" stretch mesh size) was used most parts of the lagoon, baited hooks and lines were used along the shore; large as well as small species of fish were caught by this method. For the bottom dwelling fish gill net were set at bottom for 6 hours in the early morning and late afternoon. Except the gill net other gears were used in the morning hours between $8.00 \mathrm{am}$ to $11.00 \mathrm{am}$. The fish sample data were also collected from each of the selected sites and landing sites on seasonal basis. The number of each fish species caught were enumerated, recorded and their photographs taken to ensure accurate identification to the lowest taxonomic level. In the laboratory, fish were identified

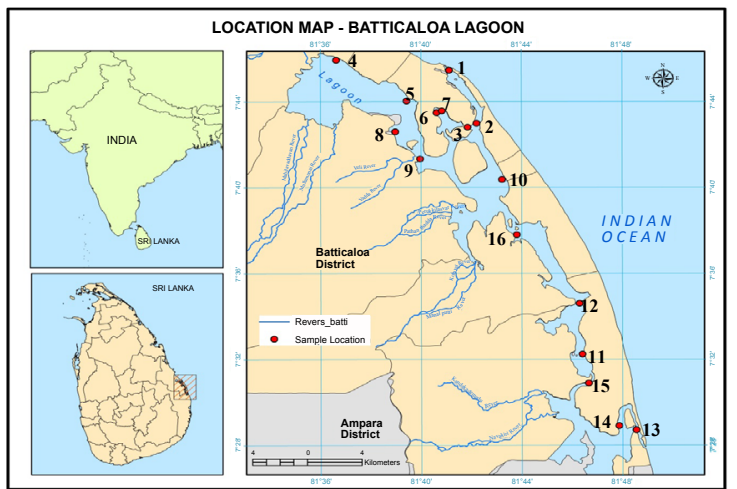

Figure 1: Batticaloa lagoon and sampling sites using keys of FAO species identification field guide for fishery purpose of Sri Lanka $[14,15]$. Fish abundance was determined by monitoring and recording the fish catch data from various locations in the lagoon. Diversity index were calculated as follows

Richness index was expressed using Margalef's richness index (d)

$$
\begin{aligned}
& \text { Margalef's Index }(d)=(S-1) / \ln N \\
& \text { d=Margalef's index } \\
& \text { S=total species number }
\end{aligned}
$$$$
\mathrm{N}=\text { total number of individuals of fish caught. }
$$$$
\text { Shannon-Wiener Diversity Function }
$$$$
H^{\prime}=-\sum_{i=1}^{s} p i \ln p i
$$$$
\mathrm{H}^{\prime}=\text { Shannon-Wiener Diversity Function }
$$$$
S=\text { total species number }
$$$$
\mathrm{p}_{\mathrm{i}}=\text { proportion of each species in each sample }
$$

Simson's Index

$\mathrm{D}=1 / \sum p i^{2}$

$\mathrm{D}=$ Simson's index

Pielou's evenness

$\mathrm{J}=H^{\prime} / \ln S$

$\mathrm{J}=$ Pielou's evenness

$$
\begin{aligned}
& \text { Equitability }(E)=d / S \\
& \text { E=Equitability }
\end{aligned}
$$

\section{Statistical analysis}

A comparison of the data collected at the different stations was made using a one-way ANOVA. Differences between seasons were tested using a t-test after verifying normality using the KolmogorovSmirnov test. Correlations between the numerical abundance and physiochemical parameters were calculated by using Pearson correlation. Diversity indices were calculated using PRIMER software Version 6.1.2 (Plymouth Routines of Multivariate Ecological Research) software.

\section{Results}

\section{Water quality characteristics}

The observed seasonal and spatial variation of mean physicochemical water quality parameters shown in the Figure 2 . The mean salinity was not identical along the sampling stations ranging from 0.00 \pm 1.95 (Site 15) in north-East monsoonal period to $30.25 \pm 1.19 \mathrm{ppt}$ (Site 1) in second inter monsoonal period. The seasonal variation of salinity indicated that there was significant difference $(p=0.002)$ at the $95 \%$ confidence level.

Dissolved Oxygen (DO): The mean concentration of DO fluctuate from $4.94 \pm 0.56$ (Site 15) to $10.75 \pm 0.38 \mathrm{mg} / \mathrm{L}$ (Site 5). The maximum value recorded in first inter monsoonal period while lowest in NorthEast monsoonal period. There was statistical significant difference ( $\mathrm{p}=$ 0.000 ) at the $95 \%$ confidence level in DO among the season. 
Citation: Harris JM, Vinobaba P (2013) Assessment the Present Status of Batticaloa Lagoon, Sri Lanka by means of Water Quality, Fish Diversity

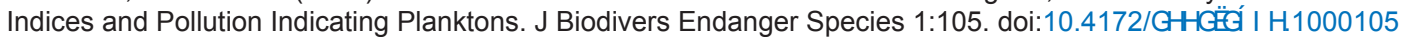
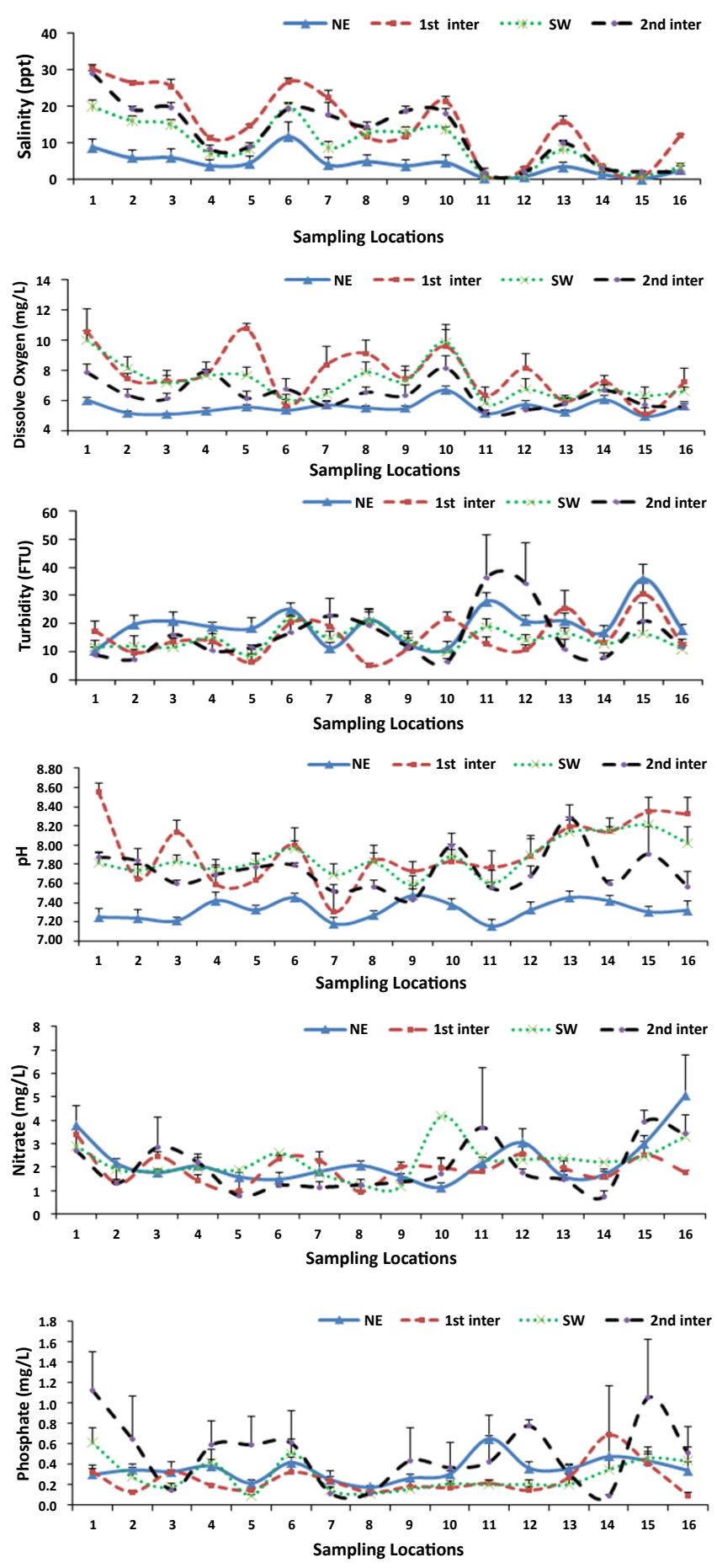

Figure 2: Mean variation of water quality parameters with locations and seasons

The lagoon water is quite clear in the most of the time but turbid at the peak of rainy season. In all sampling points the mean turbidity during North-East monsoonal period found to be high than other season. The mean turbidity variation ranging from $5.14 \pm 0.31$ (Site 8) during the first inter monsoonal period and $36.43 \pm 1.42$ FTU during the Second inter monsoonal period. There was no statistical significant difference $(\mathrm{p}=0.190)$ at the $95 \%$ confidence level among the season.
The mean nitrate level varying between $0.75 \pm 0.12$ (Site 14) to 5.06 \pm 1.23 (Site 16). Maximum value of nitrate was found in the southern sector of the lagoon during the North-East monsoonal period while lowest in North-East monsoonal period. The seasonal variation of nitrate was not significant $(\mathrm{p}=0.585)$ at the $95 \%$ confidence level.

The mean phosphate concentration ranged between $0.09 \pm 0.16$ (Site 14 and 16) during inter monsoonal period to $1.06 \pm 0.15$ (Site 15) during the second inter monsoonal period. The seasonal variation of phosphate was significant $(\mathrm{p}=0.005)$ at the $95 \%$ confidence level.

The mean $\mathrm{pH}$ of the lagoon water recorded between comfortable range $7.15 \pm 0.42$ (Site 11) to $8.55 \pm 0.78$ (Site 1). Highest value of $\mathrm{pH}$ was found in the northern sector of the lagoon during the first inter monsoonal period while lowest in North-East monsoonal period. The seasonal variation of $\mathrm{pH}$ was significant $(\mathrm{p}=0.000)$ at the $95 \%$ confidence level.

Correlation analyses revealed that among the environmental variables measured in this study, salinity, turbidity and dissolve oxygen were showed the negative correlation $\mathrm{r}=-0.813, \mathrm{r}=-0.648$ and $\mathrm{r}=-$ 0.914 respectively with fish numerical abundance [21].

A total of 10511 fish specimens were collected, belonging to 96 species representing of 41 families. Sixty one per cent (61.13\%) of the collected species correspond to an estuarine dependent component (30 species), followed by $21.36 \%$ marine seasonal (40 species), $13.66 \%$ freshwater component ( 14 species), and very few are $3.83 \%$ reef associates (10 species) total in numerical abundance. Ambassis gymnocephalus dominating the catch in estuarine component while Leiognathus equulus, Oreochromis niloticus and Caranx sexfasciatus dominating in marine seasonal, freshwater component and reef associates respectively. Margalef's species richness values ranging from 9.047 (site 1) to 2.130 (site 12). Shannon-Weiner index and Simpson index also best (3.792) at site 1 low (2.199) at site 12 but Pielou's evenness found to be maximum (0.916) at site 4 while lowest value (0.849) recorded at site 3 shown in Table 2 .

Among the identified 55 species of phytoplankton only Euglenoids, Nitzschia, Anabaena, Microcystis, Oscillatoriya and Amphidinium were found to be as pollution indicator. On comparative basis low zooplankton availability only species found to be as indicator such as Rotifera, Euplotes and polychaetes.

\section{Discussion}

The apparent pollution impact associated with various types of land use practices in the catchments of the Batticaloa lagoon has been variously attributed to increased siltation, eutrophication. The site 5 is bordered by mangrove stands which are heavily exploited for fuel wood and security purposes therefore feeding grounds are also severely damaged. However, recent anthropogenic activities in the lagoon will have adverse impacts in natural system of lagoon environment. This situation threatens the sustainability of fisheries productivity.

The system evidenced temporal variations in salinity, having observed five different regimes: freshwater $(0$ to $<0.5 \%$ ), oligohaline $(0.5$ to $<5.0 \%$ ), mesohaline ( 5.0 to $<18.0 \%$ ), polyhaline (18 to $30.0 \%$ ) and Euhaline (30 to $40 \%$ ). Sampling points 1 and 13 greatly influenced by sea water intrusion through the bar mouth. Expectedly, the salinity of northern sector of this lagoon was 3 times higher than the southern sector, which has limited and intermittent contact with Bay of Bengal. These salinity gradients greatly influence the species composition and migration of fish. Northern sector consists of marine seasonal 


\begin{tabular}{|c|c|c|c|c|}
\hline \multirow{2}{*}{ Site } & \multirow{2}{*}{ Place } & \multicolumn{2}{|c|}{ Coordinate } & \multirow{2}{*}{ Characteristics } \\
\hline & & Latitude & Longitude & \\
\hline 1 & Paalameenmadu & $7^{\circ} 45^{\prime} 29.58^{\prime \prime} \mathrm{N}$ & $81^{\circ} 41^{\prime} 14.39^{\prime \prime} \mathrm{E}$ & Sea grasses, Mangrov \\
\hline 2 & Kallady & $7^{\circ} 43^{\prime} 23.42^{\prime \prime} \mathrm{N}$ & 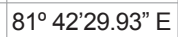 & Aquatic vegetation \\
\hline 3 & Kottamunai & $7^{\circ} 42^{\prime} 58.15^{\prime \prime} \mathrm{N}$ & $81^{\circ} 41^{\prime} 48.64^{\prime \prime} \mathrm{E}$ & Muddy fine clay \\
\hline 4 & Eravur & $7^{\circ} 45^{\prime} 14.81^{\prime \prime} \mathrm{N}$ & $81^{\circ} 35$ & Muddy \\
\hline 5 & Sathurukondan & $7^{\circ} 44^{\prime} 31.96^{\prime \prime} \mathrm{N}$ & $81^{\circ} 38^{\prime} 50.23^{\prime \prime} \mathrm{E}$ & Fine sand, $M$ \\
\hline 6 & Thiruperumthurai & $7^{\circ} 43^{\prime} 12.39^{\prime \prime} \mathrm{N}$ & $81^{\circ} 42^{\prime}$ & Clay \\
\hline 7 & Urani & $7^{\circ} 43^{\prime} 07.22^{\prime \prime} \mathrm{N}$ & $81^{\circ} 41^{\prime} 20.27^{\prime \prime} \mathrm{E}$ & Fine sand \\
\hline 8 & Valayaravu & $7^{\circ} 42^{\prime} 48.07^{\prime \prime} \mathrm{N}$ & $81^{\circ} 39^{\prime} 24.88^{\prime \prime} \mathrm{E}$ & Aquatic moss, Mangroves \\
\hline 9 & Vavunativu & $7^{\circ} 41^{\prime} 45.15^{\prime \prime} \mathrm{N}$ & $81^{\circ} 39^{\prime} 36.73^{\prime \prime} \mathrm{E}$ & Aquatic moss, Mangroves \\
\hline 10 & Kattankudy & $7^{\circ} 39^{\prime} 38.64^{\prime \prime} \mathrm{N}$ & $81^{\circ} 43^{\prime} 59.98^{\prime \prime} \mathrm{E}$ & Fine and granular sand \\
\hline 11 & Kaluthawe & $7^{\circ} 32^{\prime} 39.57^{\prime \prime} \mathrm{N}$ & $81^{\circ} 46^{\prime} 29.62^{\prime \prime} \mathrm{E}$ & Muddy, A \\
\hline 12 & Chettipalayam & $7^{\circ} 43^{\prime} 07.22^{\prime \prime} \mathrm{N}$ & $81^{\circ} 41^{\prime} 20.27^{\prime \prime} \mathrm{E}$ & Muddy, Aquatic weeds \\
\hline 13 & Kallaru & $7^{\circ} 29^{\prime} 47.36^{\prime \prime} \mathrm{N}$ & $81^{\circ} 48^{\prime} 27.36^{\prime \prime} \mathrm{E}$ & Rocky \\
\hline 14 & Kallaru stream & $7^{\circ} 28^{\prime} 19.08^{\prime \prime} \mathrm{N}$ & $81^{\circ} 47^{\prime} 30.81^{\prime \prime} \mathrm{E}$ & Clay loam, Cat tail \\
\hline 15 & Pattiruppu & $7^{\circ} 30^{\prime} 32.08^{\prime \prime} \mathrm{N}$ & $81^{\circ} 46^{\prime} 15.29^{\prime \prime} \mathrm{E}$ & Muddy, Aquatic weeds \\
\hline 16 & Kokkaticholai & $7^{\circ} 38^{\prime} 01.17^{\prime \prime} \mathrm{N}$ & $81^{\circ} 43^{\prime} 59.98^{\prime \prime} \mathrm{E}$ & Moss, Aquatic weeds \\
\hline
\end{tabular}

Table 1: Sampling sites coordinates and their characteristics

\begin{tabular}{|c|c|c|c|c|c|c|c|}
\hline Site & $\mathbf{S}$ & $\mathbf{N}$ & $\mathbf{d}$ & $\mathbf{J}^{\prime}$ & $\mathbf{H}^{\prime}$ (loge) & 1-Lambda' & $\mathbf{E}$ \\
\hline 1 & 68 & 1646 & 9.047 & 0.899 & 3.792 & 0.970 & 0.133 \\
\hline 2 & 54 & 1036 & 7.633 & 0.915 & 3.648 & 0.967 & 0.141 \\
\hline 3 & 33 & 750 & 4.834 & 0.849 & 2.968 & 0.925 & 0.146 \\
\hline 4 & 25 & 537 & 3.818 & 0.916 & 2.948 & 0.938 & 0.153 \\
\hline 5 & 44 & 758 & 6.485 & 0.913 & 3.456 & 0.961 & 0.147 \\
\hline 6 & 34 & 596 & 5.164 & 0.853 & 3.008 & 0.925 & 0.152 \\
\hline 7 & 29 & 540 & 4.450 & 0.896 & 3.018 & 0.940 & 0.153 \\
\hline 8 & 28 & 556 & 4.272 & 0.889 & 2.962 & 0.937 & 0.153 \\
\hline 9 & 27 & 528 & 4.147 & 0.876 & 2.887 & 0.924 & 0.154 \\
\hline 10 & 40 & 670 & 5.993 & 0.880 & 3.246 & 0.950 & 0.150 \\
\hline 11 & 15 & 353 & 2.386 & 0.851 & 2.303 & 0.872 & 0.159 \\
\hline 12 & 13 & 280 & 2.130 & 0.857 & 2.199 & 0.864 & 0.164 \\
\hline 13 & 27 & 525 & 4.151 & 0.849 & 2.800 & 0.909 & 0.154 \\
\hline 14 & 14 & 400 & 2.170 & 0.906 & 2.390 & 0.896 & 0.155 \\
\hline 15 & 23 & 680 & 3.373 & 0.872 & 2.734 & 0.921 & 0.147 \\
\hline 16 & 20 & 518 & 3.040 & 0.876 & 2.625 & 0.914 & 0.152 \\
\hline Total & $\mathbf{9 4}$ & $\mathbf{1 0 3 7 3}$ & & & & & \\
\hline
\end{tabular}

$\mathrm{S}=$ Total species, $\mathrm{N}=$ Total individuals, $\mathrm{d}=$ Margalef's species richness, $\mathrm{J}$ ' $=$ Pielou's evenness, $\mathrm{H}^{\prime}$ = Shannon index (e base), 1-lambda = Simpson index and $\mathrm{E}=$ Equitability

Table 2: Diversity indices with locations

and estuary dependent species but only fresh water species abundant in southern tail of this lagoon. Salinity is also an important factor in determining the amount of oxygen that a body of water can hold. As the amount of dissolved salt in water increases, the amount of oxygen the water can hold decreases [22]. Mean richness and diversity indexes achieved their highest values during the mesohaline period. On the other hand, mean abundances were highest during the oilgohaline period.

The turbidity of certain location of this lagoon (Sampling point 11, 12 and 15) far exceeded that of the threshold level. This was indicative anthropogenic pressures although the magnitude and frequency of the pressures is not uniform. As a result species richness found to lower level in these locations. Furthermore high turbid condition reduce the sunlight penetration finally reduce the availability of phytoplankton might be the reason for lower species richness.

The dissolve oxygen concentration was fairly stable throughout the sampling period. Due to the low photosynthetic rates in eutrophic areas (Site 7 and 13) DO level were found to be low. Whereas the DO concentration in certain location found to be low, it may be due to the elevation of water temperature and increase in the rate of bacterial decomposition of organic matter. Decomposition of water hyacinth also takes significant amount of oxygen from this water column where they were abundant.

Lower dissolved oxygen concentration was usually observed at the height of wet seasons during which nutrients and debris are flushed into the Batticaloa lagoon with influx of fresh water from the adjoining rivers. Also oxygen depletion also noticed in the two eutrophic areas during the latter part of August. The dissolved oxygen levels water $\mathrm{pH}$ affects metabolism and physiological processes of fish and also exerts considerable influence on toxicity of ammonia and hydrogen sulphide as well as solubility of nutrients and thereby water fertility [23]. But in the case southern part at the sampling points 15 and 16 accumulation of seasonally abundant water hyacinth might cause deteriorating water quality by means of altering the $\mathrm{DO}$ and $\mathrm{pH}$.

\section{Fish species diversity and abundance}

To get a better description of fish diversity, a measure of diversity indices, species richness and evenness of their distribution were undertaken in Batticaloa lagoon (Table 2). The study finding showed that ichthyo diversity of study area is reducing with low salinity, high pollution load, and habitat modification by anthropogenic impact, low bottom vegetation, low dissolve oxygen concentration and ample food resources. In certain location (sites 11, 12 and 14) reduced fish diversity leading to creates extinction of several native fishes (Channa Striata, Heteropneustes fossilis and Puntius dorsalis) and commercial important species (Anguilla bicolor, Hemiramphus far, Liza melanoptera, Siganus oramin and Epinephelus coioides). These consequences eventually create instability of fisher folk's livelihood in this region. Tolerant species such as Oreochromis niloticus and Etroplus suratensis thriving well in polluted area. However certain commercially important species threatened by deteriorating water quality in other locations.

Species richness is the total number of species presents in a given area or sample whereas diversity takes into accounts how individuals are distributed amongst those species, i.e., the species frequency distribution. In fact, it turns out that nearly all quantitative measures of diversity are some combination of two components, species richness and evenness, where evenness describes how equally individuals are distributed amongst the species. The relative abundance of rare and common species is called evenness. Communities dominated by one or a few species have a low evenness while those that have a more even distribution of species have a high evenness. Species diversity includes both species richness and evenness. Communities with a large number of species that are evenly distributed are the most diverse and communities with few species that are dominated by one species are the least diverse.

Species richness influenced by higher salinity in sites 1,2, 3, 13 while sites 4,6 and 10 by habitat modification by waste disposal. Site 1 with the lowest measurements of pollution had communities high in species richness, diversity and individual numbers. Species richness, diversity and individual abundance were all very low at locations closer to the sewage disposal sites (Site 3, 4, 6 and 8). Present survey highlighted differences in water chemistry and seasonal changes affect the total abundance of commercially important fish species such as Chanos chanos, Mugil cephalus and Caranx sexfasiatus. Locations 4, 6, 10, 11, 12 and 15 become progressively polluted by the different anthropogenic 
Citation: Harris JM, Vinobaba P (2013) Assessment the Present Status of Batticaloa Lagoon, Sri Lanka by means of Water Quality, Fish Diversity

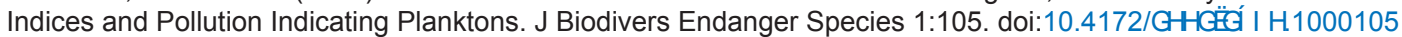

Page 5 of 6

impacts along its course. Thus lagoon at these locations currently faces number of serious environmental and ecological challenges. The highest species richness was noticed in site 1 coinciding with favorable condition such as sea water intrusion, sea grass for feeding and spawning and ample food resources. The lowest species richness found at the site 12 probably due to the murkiness of water.

Shannon-Weiner index $\left(H^{\prime}\right)$ affects both number of species and evenness of their population. Diversity is maximum when all species that made up the community are equally abundant (i.e. have a similar population sizes). The diversity is partly a function of the variety of habitats; the more varied habitats tend to be inhabited by a large number of species than less variable ones. Secondly the older habitats usually contain more species than younger ones. Warmer temperatures, availability and stability of food result in high level of diversity. The results revealed that sampling site 1 has higher Shannon - Weiner index $\left(H^{\prime}\right)$ because of this site s have variety of micro habits (mangrove swamps, sea grass bed, estuarine region) and well availability of planktons as food. The sampling point 6 is considered to be highly polluted probably due to the disposal of domestic waste, effluent water withdrawal from shrimp farm which in turn reduction in size of the popular Oreochromis niloticus in recent years.

Over the years, ecological studies have shown that there is a good relationship between environmental characteristics and plankton community structure [24]. Similarly, Chindah [25] indicated that plankton and have been diagnostic in assessing water quality and hydrological status. Main phytoplankton species available in the Batticaloa lagoon belong to five different groups with a total of 55 species.

Occurrence such species as Nitzschia, Microcystis (blue-green algae) is a very good indicator of pollution. Microcystis has a relatively low phosphorus requirement and has the ability to utilize sulphur as an alternative to phosphorus in its metabolism [26]. Furthermore, the prevalence of Euglenoids may be a further indication of organic contamination. Most important here are phosphates and nitrites, which favour the phytoplankton growth mainly in surface light layers. Appreciable quantity of Nitzschia and Nitrogen fixing phytoplankton (Anabaena) observed in sites 3 and 6 indicates, this location is subjected to more nitrate pollution. Most of the dominant species of phytoplankton were not considered as harmful and dangerous for human health. However, certain species of Anabaena, Microcystis, Oscillatoriya are known to produce certain neurotoxin, hepatotoxin and skin damages. In addition Amphidinium sp also observed in the lagoon produce biologically active haemolytic compounds and may be implicated in ciguatera (phytotoxin) these have to viewed as lagoon food safety.

The frequency of rotifers alongside other organisms could be an additional indicator to the level of contamination in sites 4 and 6. Ciliates Euplotes sp dominated in higher salinity condition it has also dominated where the location of temperature and organic matter levels are high in site 3. Zooplankton density is not only influenced by the increment of water temperature but also by the decrease of nitrate concentration. Due to the high temperature and high nitrate concentration at site 8 the cause for low zooplankton availability on comparative basis. The organisms found being dominated by polychaetes and rotifer species at sampling point 6 symptomatic of high pollution and low DO [27] due to discharge of shrimp farm effluents. In contrast, the copepod could be considered as a target species in highly eutrophic areas.

\section{Findings}

Based on the results of the present study it can be stated that, seasonal fluctuation water quality and anthropogenic threatened the Ichthyo diversity of Batticaloa lagoon. Sri Lanka. Phytoplanktons of Chlorella, Oscillatoria, Nitzschia, Cymbella and Zooplanktons of Rotifers, Polychaetes were found to be good indicators of water pollution. From this evidence that places where the above mentioned planktons are eminence the area is polluted needs restoration.

\section{Future Consideration}

Deterioration of water quality if prevent which in turn may help to increase the fish production. In addition control and eradiation of water hyacinth also will definitely help to improve the fish productivity of this lagoon. Continuous environmental monitoring is required for understanding the impact of natural and anthropogenic processes in the lagoon ecosystem. The study highlighted the need for the stakeholder to watchful of anthropogenic threats harmful fishing practices which may cause extinction of fish species. Identified extreme risk area to give an immense importance for effective monitoring and conservational programs are urgently needed. New indicators of fish resources are needed as well. Such indicators could use a classification by functional group. These kinds of data allow researchers to better analyze anthropogenic effects on the management of lagoon pelagic fish populations.

\section{Acknowledgement}

We would like to express our profound gratitude to National Science Foundation, Sri Lanka for their financial assistance under the competitive research grant no. RG/2011/ES/04. We are indebted to convey our heartfelt thanks to fisher folks of Batticaloa lagoon for their kind Corporation and valuable help in various ways to carry out the project work successfully.

\section{References}

1. Blaber SJM (2000) Tropical Estuarine Fishes: Ecology, Exploitation and Conservation. 2: 148-157.

2. Gray JS (1997) Marine bio diversity: Patterns, threats and conservation need Biodiversity Conservation, 6: 153-175.

3. Small C, Nicholls R (2003) A Global analysis of Human settlement in coastal zone. Journal of Coastal Research 19: 584-599.

4. Pandey K, Shukla JP (2007) Fish and Fisheries, $2^{\text {nd }}$ edition, Rastogi Publications, Meerut, India.

5. Eruola AO, Ufoegbune GC, Awomeso JA, Adeofun CO, Idowu OA et al (2011) An assessment of the effect of industrial pollution of Ibese River, Lagos, Nigeria. Journal of Environmental Science and Technology 5: 608-615.

6. Ganasan V, Hughes RM (1998) Application of an index of biological integrity (IBI) to fish assemblages of the rivers Khan and Khsipra (Madya Pradesh), India. Freshwater Biology. 40: 367-383.

7. Zampella RA, Bunnell JF, Laidig KJ, Procopio NA (2006) Using multiple indicators to evaluate the ecological integrity of a coastal plain stream system. Ecological Indicators. 6: 644-663.

8. Moyle PB, Crain PK, Whitener K, Mount JF (2003) Alien fishes in natural streams: Fish distribution, assemblage structure, and conservation in the Cosumnes River, California, U.S.A. Environmental Biology of Fish 68: 143-62.

9. Webber DF, Webber MK (2005) The water quality of Kingston Harbor: evaluating the use of the planktonic community and traditional water quality indices. Journal of Chemical Ecology 14: 357-374.

10. Choi JK, Shim JH (1986) The ecological study of phytoplankton in Kyeongg Bay, Yellow Sea. Journal of the Oceanological Society of Korea. 21: 156-170.

11. APHA, American Public Health Association. (1992). In Standard Methods for the Examination of Water and Wastewater. $20^{\text {th }}$ edition, Pleneum Press Washington, DC, USA 
Citation: Harris JM, Vinobaba P (2013) Assessment the Present Status of Batticaloa Lagoon, Sri Lanka by means of Water Quality, Fish Diversity

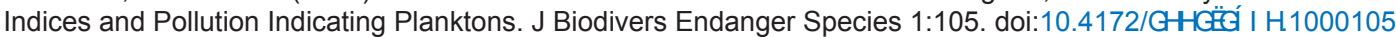

12. Edmondson WT (1992) Algae, key to genera. In Fresh water Biology. (2 $2^{\text {nd }}$ edition) International Books \& periodicals supply services. New Delhi, India.

13. Todd CD, Laverack MS, Boxshall GA (1996) Coastal marine Zooplankton. A practical manual for students. ( $2^{\text {nd }}$ edition). Cambridge University Press.UK

14. De Bruin GHP, Russell BC, Bogusch A (1994) Species identification field guide for fishery purpose. The marine fishery resources of Sri Lanka. Publication of Food and Agricultural Organization (FAO) of the United Nations.Rome, Italy.

15. Munro SR (1955) The Marine and fresh water fishes of Ceylon. Department of external affairs, Canberra, Australia.

16. Clarke KR, Warwick RM (1994) Change in Marine Communities: An Approach to Statistical Analysis and Interpretation. Natural Environmental Research Council, Bournemouth.UK.

17. Shannon CE, Weiner W (1949) The mathematical theory of communication. Univ. Illinois Press. Urbana.

18. Simpson EH (1949) Measurement of diversity. Nature 163: 688-689

19. Pielou EC (1966) The measurement of diversity in different types of biological collection. Journal of Theoretical Biology. 13: 131-144.
20. Krebs CJ (1978) Ecology: The experimental analysis of distribution and abundance. Harper Intellectual Edition, New York, USA.

21. Gelwick PF, Alkin S, ArrintonDA. Winemiller KO (2001) Fish assemblage structure in relation to environmental variation in a Texas Gulf coastal wetland. Estuaries 24: 285-296.

22. Kennish, M.J. (2002) Environmental threats and environmental future of estuaries. Environ Conserv 29: 78-107.

23. Lamptey E, Armah AK (2008) Factors affecting macrobenthic fauna in a tropica hypersaline coastal lagoon in Ghana, West Africa. Estuaries and Coasts 31 1006-1019.

24. Onyema IC, Nwankwo DI (2006) The epipelic assemblage of a polluted estuarine creek in Lagos, Nigeria. Pollution Research 25: 459-468.

25. Chindah AC, Braide SA (2003) Epipelic algal of tropical estuary Case of Stable and invariable seasonal community. Polish Journal of Ecology 1: 91-99.

26. Gerloff GC, Fitzgerald GP, Skoog F (1952) The mineral nutrition of Microcystis aeruginosa. American Journal of Botany 39: 26-32.

27. Ismail NS (1992) Macrobenthic invertebrates near sewer outlets in Duba creek, Arabian Gulf. Marine Pollution Bulletin 24: 77-81. 